\title{
Unresolved Issues of Self-Representation
}

\author{
Hazel Markus ${ }^{1}$ \\ University of Michigan
}

The seven papers included in this volume converge in many of their assumptions about the representation of the self, yet a number of issues remain unresolved. These issues, including the structure and functioning of self-representations, and the role of negativity, affect, and the "other" in the self-system, are discussed here.

KEY WORDS: self-representation; negativity; affect; the other; self-system.

\section{UNRESOLVED ISSUES OF SELF-REPRESENTATION}

This is a fascinating collection of papers. Each piece is noteworthy in at least one respect and together they comprise an unusually useful, important volume. Harter's paper is an insightful integration of the literature on selfrepresentation in children, as well as a cogent appeal for attending to developmental differences in the nature and functioning of self-representations. Segal and Vella's replicates and extends their work on cognitive organization in depression, and raises the thorny question of the presence of negativity in all self-systems - viable and nonviable alike. The work of Hope, Rapee, Heimberg, and Dombeck is an intriguing exploration of the self-schemas of social phobics. Bemis and Hollon contribute a thoughtful, engaging piece on assessing the operation of self-schemas in eating disorders, and provide a suggestion about the cognitive essence of these schemata. The Hammen and Goodman-Brown paper, in an important extension of earlier work, examines the potential role of self-schemas in the onset of depression in children. Finally, Safran, Segal, Hill, and Whiffen discuss a number of 48106. 
methodological issues pertinent to the assessment of self-schemas, and then pose the highly significant and consequential question of the role of the "other" in the formation and functioning of self-schemas.

As a group these papers draw attention to a number of important conceptual and methodological issues in research on the representation of the self. I will focus here on the conceptual issues because many of the methodological concerns have been thoroughly discussed in a recent paper by Segal (1988) on the self-schema construct in depression. Overall, these papers reveal an impressive number of shared assumptions about representations of the self, a diversity of unresolved issues, and some areas of potential controversy.

\section{The Self as a Collection of Self-Schemas}

The authors of these papers hold fairly similar views of the nature and functioning of the self-system. All of the theorists included here are true to a general cognitive model of the self that has its roots in the early work of Rogers (1951), Kelly (1955), Combs and Snygg (1959), Bruner (1957), and Allport (1955). The self envisioned here is a dynamic one; it is not a static entity that simply reflects past experience. It is active, forceful, and capable of change (see Markus \& Wurf, 1987). Further, the self is a multidimensional, multifaceted set of structures that plays a critical role in organizing all aspects of behavior. These structures, called self-schemas in most of the papers in this volume, provide the categories by which to render experience meaningful. As Kegan (1982) says, "human being is the composing of meaning" (p. 11), and it is the consensus of these contributors that structures of the self are front and center in the meaning-making process. Happily, in this volume, concerns over whether the self-structure is a "unique" structure, or whether the available data on self-structure pass the gold standard test for what is a "real" cognitive structure (see, e.g., Higgins \& Bargh, 1987) have been put aside in favor of a variety of other questions.

In this emerging view of the self, each person is hypothesized to hold a diverse array of representations about the self - the good me, the bad me, the not me, the actual me, the ideal me, the ought me, the possible me, the undesired me, the hoped-for me, the expected me, the feared me, and the shared me (i.e., me-in-relation-to-my mother; me-in-relation-to my spouse, etc.). Of this universe of self-representations, only some will become focal for the individual and receive a high degree of cognitive, affective, or somatic elaboration. Those representations that, for whatever reason, become the target of such intensive elaboration are the self-schemas. And it is the self-schemas that will dominate consciousness, and perhaps unconsciousness, and that can be considered the "core" self. 
Although individuals of a given age or a given linguistic or cultural group are likely to share some self-representations, the view here is that individuals differ importantly in the nature, and perhaps in the number of domains in which they define themselves. People with a self-schema in a particular domain or for a specific issue-whether it is for their roles as parent, spouse, or friend, for their expertise about sports, food, or the stock market, for their attributes of creativity or independence, or for their fears of being fat or anxious in large gatherings - consider these domains and issues to be of critical personal importance. As such, they will maintain an enduring investment and commitment to these self-defining domains.

Individuals are assumed to construct self-representations from the information contained in their unfolding life experiences. As they do so, they gain an impressive knowledge base, perhaps even a genuine expertise, about their abilities, their preferences, their hopes and fears. Such self-construction does not avail itself of information indiscriminately, rather it is selective and creative. And once established the influence of these self-schemas is pervasive. They determine what to pay attention to in one's self and others, what to think about, what to remember, as well as the nature of many of one's judgments, inferences, and decisions. For example, as the studies by Hope et al. and Segal and Vella (this volume) indicate, subjects take longer to name the color of the ink that a word is written in if the word is self-relevant than they do if it is irrelevant. Self-relevant stimuli demand and divert attention; they cannot be ignored.

\section{The Structure and Functioning of Self-Representations}

Although it is not addressed explicitly, one has the impression from most of these papers that the self-schemas associated with emotional disorders will be essentially like more viable self-schemas. What distinguishes the schemas of emotional disorder is only the content of the self-schema. Thus depressives will have self-schemas relevant to depression, social phobics will have self-schemas relevant to their fear of social situations, and those with eating disorders will have schemas relevant to their eating disorders. This is a very reasonable initial assumption. And indeed, many of the achievements of cognitive therapy are an outgrowth of the assumption that some important aspects of emotional disorders derive from domain-specific selfschemas that are structuring experience in just the ways hypothesized by schema theory.

The critical issue raised by these papers, however, is whether it is content alone that distinguishes a maladaptive self-schema. What is the difference between Joan who weights 110 pounds, is 5'4", and lives a life centered almost entirely on a fear of someday weighing 120 pounds, and Jane who 
is of identical height and weight but who doesn't know her precise weight and has never dieted a day in the life? Is the difference only a matter of the content of their self-defining schemas? With the exception of the Bemis and Hollon piece, no more than passing attention is given to possible differences in the functioning of self-representations of those with emotional disorders. Yet if one makes the plausible assumption that what one thinks about influences how one thinks, it is likely that the self-schemas of the depressive or the social phobic will function differently from self-schemas organized around other content domains. Consistent with this notion, Bemis and Hollon suggest that because of the needs being served by body weight schemas, weight may be a unusually powerful dimension in the perceptual tool-kit of anorexics. As a consequence, their schema-relevant judgments may be even more extreme and engender even more confidence than is typical of schemarelevant judgments. Bemis and Hollon also suggest that schemas accompanying eating disorders may be particularly resistant to counter-schematic feedback, perhaps more so than schemas in other domains. Such extreme resistance, they argue, derives not only from the desire to be thin or not to be fat, but from an attempt to simplify and gain control over events by reducing the number of their important life tasks (see Cantor \& Kihlstrom, 1987).

Indications that the self-schemas of those with emotional disturbances produce different, stronger, or more powerful effects on processing than other types of self-schemas lead to the suggestion that the former self-schemas (e.g., the weight-related self-schemas of eating-disordered subjects) may be especially well-elaborated and likely to assume centrality in the self-systems of these individuals. To this point, however, very little attention has been given to analyzing the structure of either a single self-schema or the overall self-system. Self-schemas are hypothesized to be complex, highly integrated structures. Presumably, they consist of information about the self that is organized into a unified structure such that if one part of the structure is activated, the entire structure is activated. Yet because the field currently lacks an obvious methodology for evaluating the degree or extent of cognitive structure, there have been few direct tests of these assertion.

Stein (1989) in a recently completed study, suggests that some of the methodologies previously used in the study of cognitive style and cognitive structure might be profitably applied to the study of the structure of selfrepresentations. Using a revision of Zajonc's (1960) approach to the assessment of cognitive structure, she carried out a study that required subjects to freely generate as many characteristics as they felt described them in particular domains (e.g., as a student or as a son), and then to determine whether those descriptors fell into some natural groupings and subgroupings. Further, she asked subjects to determine for each of the self-generated characteristics listed which of the other characteristics would also change if this 
characteristic were to change. This later measure allowed a determination of how much the schema was organized around any single element. For each subject Stein was then able to determine the mean complexity of a given schema (i.e., the extent to which the self-conceptions were organized in a hierarchical structure) and the mean organization (i.e., the extent to which the schema was organized around a single self-conception).

Following a procedure in which these students were told they had done poorly on a newly developed test of intelligence, Stein found that subjects with high integration of the student schema (i.e., where the descriptors are organized into hierarchical structure and where the descriptors are organized around a single core element) appeared to take account of the feedback in subsequent self-evaluations. In contrast, subjects with low integration of the student schema denied the feedback and simply reasserted relevant positive aspects of the self.

A procedure like that of Stein's might allow investigators to determine whether the schemas associated with particular emotional disorders have a distinctive structure. Emotional disorders may be associated with low integration of self-schemas in positive domains and high integration of self-schemas in negative domains. Techniques developed to explore variation in the structure in self-representation would also allow a close-up look at the contents of the relevant self-schemas, and perhaps some determination of the nature of their core or unifying elements. For example, two pieces in this volume (Bemis \& Hollon; and Hope et al.) suggest that the self-representations of disturbed individuals may not be in the declarative form (e.g., I am fat, I am weak) often assumed to characterize self-schemas. Rather, Bemis and Hollon find that eating-disordered individuals often make conditional statements like, "If I am fat, I cannot ..." and Hope et al. report that social phobics report that if they blush or shake too much "she will think I am a wimp." Conditional statements like this may be at the heart of all self-schemas. To investigate such questions will require techniques that allow a detailed examination of the content of specific schemas.

Beyond efforts to measure the structure of the organization of a single schema, it could also be useful to assess the structure of the entire self-system. Linville $(1982,1987)$ has been concerned with just this problem and uses a task in which subjects are required to sort trait descriptors into meaningful groups. She finds that individuals with many overlapping or redundant categories of self-description experience a greater decrease in their selfevaluation after a threat or a challenge than those with many, nonoverlapping categorizations. With further work on the structure of the self-system, one could examine, for example, whether individuals with a hierarchically organized self-system that has "self as good" or "worthy" or loved" as a super dinate category are less at risk for emotional disorder. 
A critical feature in understanding why some individuals with a particular self-schema show emotional disturbances while others do not, or in determining why some individuals construct particular self-representations in the first place, may well depend on some understanding of what other selfschemas are included an individual's repertoire. In other words, what does the embedding context for a particular self-schema look like? Once a schema gains hold and becomes dominant in regulating behavior, what other schemas are available in the individual's self-concept to balance it or offset it? For example, in our work (Markus \& Nurius, 1986; Cross \& Markus, 1987) we find that most people have some version of the "fat, dumb, and ugly" self-schema that when activated can lead to a temporary depression in which one's self, one's future, and the world are all worthless and bleak. Yet most individuals also have a variety of other, often much more well-elaborated representations of the self, that will compete with, and eventually overpower, one's "self as worthless" schema. The same appears true in the area of eating disorders. A large proportion of college women report ideation that appears identical to that of anorexics and bulimics, yet only a relatively small proportion develop serious eating disorders. The key to the difference may rest with what other self-schemas the individual has also elaborated. Thus a desire to approach the state of perfect, elegant, essential thinness may be offset by a genuine love for food. Or it may be offset by the desire for perfection in one's work or in one's relationships, concerns that may necessarily alter the single-minded pursuit of a given desired end-state.

\section{Negativity in the Self-System}

A focus on the structure of the overall self-concept and the interdependencies and connections among various representations of the self-system might also afford a better understanding of the role of negativity in the selfconcept. Showers (1989b) finds, for example, that when negativity is compartmentalized, individuals have higher self-evaluations than when the negativity is distributed throughtout the self-concept. Increasingly, self-concept researchers are attending to the findings that all individuals seem to have some negative aspects of the self-concept. Wurf (1989) hypothesizes that negative self-schemas may function to help individuals cope with the negativity in their lives, ensuring that negative experiences do not swamp the entire selfconcept. She finds, in fact, that individuals who are extremely shy (and claim that it is important to their overall self-evaluation) handle negative feedback in this domain better than individuals who deemphasize or down-play the importance of their shyness. This raises the puzzling question of whether those who have elaborated negative self-schemas may actually feel better than those who have ignored certain negative aspects of the self. 
Recently, many researchers are testing the potential positive effects of negative thoughts. Schwartz and Garamoni (1986) claim, in fact, that psychological adaptation depends on an alternation between both positive and negative states of mind. A complete segregation of the two, a focus just on the positive, may produce difficulty for the individual. Oyserman and Markus (1989) find that a balance between negative self-conceptions and positive self-conceptions in a given domain (e.g., expecting to finish school and fearing flunking out of school) is associated with positive outcomes like reduced levels of delinquency. And Cantor and colleagues (see Cantor \& Kihlstrom, 1987) show that constructing negative scenarios may actually be highly motivating.

Harter alerts clinicians to the finding that most individuals have quite fragmented, diverse selves and that this should not be considered pathological. Similarly, it now appears that negative self-representations are also commonplace, perhaps even essential to healthy functioning, and their presence in the self-system should not be automatically interpreted as signaling trouble. The commonness of negative self-representations makes the need to focus on the structure and the nature of the interdependencies of negative selfschemas among self-representations even more critical. Negative selfschemas are not all alike. What makes those associated with emotional disturbance different?

\section{Affect in the Self-System}

One major contribution of the cognitive approach is the understanding that emotional disturbances may be in part created and maintained by the particular hypotheses, theories, or conditional beliefs about the self that function to provide structure and meaning to one's experiences. In moving beyond this very significant insight, we still need to grapple with why social phobics, for example, have panic attacks in social situations, or why bulimics have such an all-consuming, unassailable fear of losing control and eating too much. It may be that the self-schemas associated with pathological disorders have a unique set of emotional or motivational representations associated with them. Representations of the self that derive from wishes or unfilled needs may have a very different form and function than representations that derive from the more straightforward perception and organization of one's own behavior. Representations that are quite privately held and built largely from one's own inferences may be quite different than representations that are shared by others and that incorporate their responses. Thus, a self-schema of being unloved that develops with the experience of a loss of parent may be quite different from the schema that develops with the knowledge and understanding that one is creative or talented in music. 
Self-schemas that have their origins in early experience, experiences that are associated with the absence or presence of anxiety in the parent and thus come to be categorized as the "good me" or the "bad me" (Sullivan, 1953) may well include a diversity of bodily representations, some of which may not be accessible to conscious awareness but which may be reinstated when the schema is activated. Schemas associated with emotional disorders may integrate all types of self-representations - neural, motor, sensory. When such a schema is triggered by events in the environment, the individual may be caught in the grip of a powerful set of reactions that are not easily offset or countered by conscious self-management techniques. The consequence of the activation of such a schema will depend on whether it is figural and focal against a ground of weaker, less well-elaborated schemas, or whether it is relatively subordinate in one's organization of self-representations at a given time.

That some schemas are so resistant to new information (the failure of the person with the eating disorder to believe that eating certain foods will not lead to uncontrollable, out-of-control eating) suggests that some selfschemas may have representations that are not easily verbalizable. These types of concerns necessarily requires an explicit consideration of the role of affect (or more broadly, other than cognitive factors) in representations of the self. One model, the one made explicit by Harter, says that affect or emotion are a consequence of the configuration of self-representations that are currently actively in consciousness (see also Singer \& Salovey, 1985). Another approach is to assume that one's experienced affect functions as a heuristic that determines whether various self-relevant events are assigned to a positive or a negative class. Fast (1985) argues that affect plays a major role in determining the connections among our experiences; it defines the similarity of ours actions and thus provides the basis of the organization of the selfconcept. Still others (Guntrip, 1971; Kemberg, 1977) suggest that each selfrepresentation contains both an affective and a cognitive component.

Furthermore, exploring the nature and functioning of the affective or motivational aspects of self-schemas may well require producing some threat, challenge, or uncertainty for the subject. As the work by Hammen and her colleagues have underscored, critical events and the mood they invoke in individuals are often an important determinant of self-schema content. The Hammen and Goodman-Brown study shows, for example, that the onset of depression is associated with particular stressors that are relevant to the schema. Similarly, Linville (1987) finds that the complexity of the self-structure only predicts well-being when the individual is in a stressful situation. Currently, most experimental explorations of the self-schemas are seldom affectively or motivationally engaging. If stress is required to throw certain 
self-representations and their functioning into high relief, then some important features of schema functioning may go uncharted if laboratory studies do not employ emotionally relevant stimuli.

\section{The Role of the Other in the Self}

An issue that emerges in several of the papers in this volume is the critical role of the other in producing and maintaining self-representation. Increasingly, self-representations are being analyzed as the truly social entities they are theorized to be. While hypothesized to reside inside one's individual's head or heart, self-schemas are in large measure interpersonal achievements. Others serve in a variety of roles, as co-producers of self-feeling and self-understanding, as monitors, as standard-bearers, or as partners in interior monologues.

Harter systemically underscores the interpersonal nature of the self. She reports that older children become increasingly sensitive to the views of others and learn to use these views to verify and refine their own self-representations. As Harter's review indicates, young children do not engage in much explicit social comparison, yet is must still be the case that the self-systems of young children are heavily dependent on the responses of others. Studies by Stern (1985) and Trevarthen (1980) suggest that, in the early stages of development, others are less valuable for their views, images, or impressions of the self than they are for the affective quality and the contingency or close alignment of their responses.

Finely tuned, contingent responding from those in the individual's social environment, particularly the early caretakers, may be a key to the development of viable self-schemas (e.g., Bowlby, 1969). And even though the development of all self-schemas is assumed to implicate others, it is quite likely that some self-schemas are tied more directly to the important people in one's life (and thus are more inherently interpersonal) than are other selfschemas.

Difficulties with representing the self in connection to others may be particularly characteristic of those with emotional disorders. Several findings from the study by Hammen and Goodman-Brown are consistent with the notion. First, the association between depression or depression onset and the occurrence of negative life events that were schema-congruent held only for interpersonal schemas and not for achievement schemas. Further, in their study, a majority of the children who became depressed after schemacongruent negative events had mothers with unipolar or bipolar affective disorders. Mothers with affective disorders may be incapable of the sensitive 
mothering that leads to signals essential for the development of an "I am loved" or and "I am worthy" self-schema. Studies of the content and structure of the self-system like those proposed earlier could be used to assess such hypotheses.

In another approach to the role of the other, rather than drawing out the interpersonal nature of the self-schema, Safran et al. explicitly discuss the notion of an "interpersonal schema." This label highlights the fact that representations of the self include the beliefs and expectations of others as well as assumptions about what is necessary to maintain this relatedness. Safran et al. also propose a number of intriguing methods for assessing such interpersonal schemas. Their paper emphasizes the need to explicitly implicate others in the development and maintenance of self-representations and identifies the relations between the self and others as an issue that will assume increasing importance in the study of representations of the self in emotional disorders. Many questions are raised. Do all schemas include representations of others? Are some schemas tied to representation of generalized others while others are tied to particular others? Are there individual differences (perhaps gender, ethnic, or cultural) in how schemas of the self incorporate others?

\section{Emerging Issues in Self-Representation}

This set of papers also reveals a number of tensions that may, and probably should, become more apparent in future work. An important first question is whether studies of the self-schemas of those with emotional disorders tell us any more than that patients are indeed bothered by what they claim to be bothered by. As Bemis and Hollon ask, do we need the Stroop test to be sure that anorexic patients have problems with weight-related stimuli? Given the consensus that individuals, indeed even very young individuals, have structures of the self that actively create and organize their experiences, what more is to be gained by further studies primarily designed to show the pervasive influence of these schemas?

As an answer to this question, some will claim that a great deal is still to be learned as we pinpoint the precise ways in which representations of the self govern our experiences. How early in the information-processing sequences are self-representations invoked, for what types of stimuli, and in which types of situations are they most powerful? Answers to these types of questions are potentially very useful in devising therapy techniques and intervention strategies.

Others will claim, however, that efforts would be better placed in exploring the interpersonal events and situations that activate various schemas and in investigating how these schemas differ in content and functioning from 
more viable self-schemas. Such efforts will involve focusing on individual maladaptive schemas, with all of their idiosyncratic content, and examining how these schemas are used to organize ongoing experience. Studying the generic body weight schema, the generic anxiety schema, or the generic self as worthless and unloved is useful only to a point. It is also necessary to see how these self-schemas are personalized and how they work within the total self-system. As Hope et al. point out, the use of standardized stimuli has obvious advantages, but such efforts may have to be coupled with an exploration of the personally relevant framings of particular domains if the role of self-representations in producing and maintaining emotional disorder is to be understood.

Another issue in need of further theoretical attention is the role of the self in the regulation of behavior. One view is that affect, motivation, the self-system, and behavior are separate, although interacting, systems. From this perspective, the basic psychological processes are distinct from the selfsystem. Self-representations influence these other systems but they are separate from them.

Another view holds that the self-system is not just a system, rather it is the system - the central system that gives meaning to one's affective, motivational, and even to one's cognitive processes. All affective reactions, all motivated actions implicate the self; the form they take and the work they do depend on the nature of the self. From such a perspective one might well question the value of trying to separate the effects of mood or affect on behavior from the effects produced by the cognitive structures of the self. Selfrepresentations carry their affect and their motivation with them, and thus motivation and affect are largely manifest in people's understandings of themselves. And this may be particularly true for self-representations associated with affective disorders. It is the " $\mathrm{I}$ " who is sad, the "I" who is afraid of people, and the "I" who will be unable to stop eating. Without the "I", needs, motives, feelings, and behaviors lose their meaning. Such a view leads to a questioning of how motivation and affect are represented in the self, and perhaps how they are differently represented by those with emotional disorders.

In sum, these papers provide a number of significant empirical inșights and theoretical suggestions. Moreover, they foreshadow a series of future challenges that will confront researchers committed to refining and extending a cognitive perspective.

\section{REFERENCES}

Allport, G. (1955). Becoming; Basic considerations for a psychology of personality. New Haven: Yale University Press. 
Bemis, K. M., \& Hollon, S. D. (1990). The investigation of schematic content and processing in eating disorders. Cognitive Therapy and Research, 14, 191-214.

Bowlby, J. (1969). Attachment. New York: Basic Books.

Bruner, J. S. (1957). Going beyond the information given. In J. S. Bruner et al. (Eds.), Contemporary appraches to cognition. Cambridge, MA: Harvard University Press.

Cantor, N., \& Kihlstrom, J. F. (1987). Personality and social intelligence. Englewood Cliffs, NJ: Prentice Hall.

Combs, A., \& Snygg, D. (1959). Individual behavior (2nd ed). New York: Harper.

Cross, S., \& Markus, H. (1987). Possible selves across the life course. Paper presented at the American Psychological Association, New York.

Fast, I. (1985). Event theory: A Piaget-Freud integration. Hillsdale, NJ: Erlbaum.

Guntrip, H. (1971). Psychoanalytic theory, therapy and the self. New York: Basic Books.

Hammen, C., \& Goodman-Brown, T. (1990). Self-schemas and vulnerability to specific life stress in children at risk for depression. Cognitive Therapy and Research, 14, 215-227.

Harter, S. (1990). Developmental differences in the nature of self-representations: Implications for the understanding, assessment, and treatment of maladaptive behavior. Cognitive Therapy and Research, 14, 113-142.

Higgins, E. T., \& Bargh, J. A. (1987). Social cognition and social perception. Annual Review of Psychology, 38, 369-425.

Hope, D. A., Rapee, R. M., Heimberg, R. G., \& Dombeck, M. J. (1990). Representations of the self in social phobia: Vulnerability to social threat. Cognitive Therapy and Research, 14, 177-189.

Kegan, R. (1982). The evolving self. Cambridge: Harvard University Press.

Kelly, G. (1955). A theory of personality: The psychology of personal constructs. New York: Norton.

Kernberg, O. (1977). Borderline conditions in pathological narcissism. International University Press.

Linville, P. W. (1982). Affective consequences of complexity regarding the self and others. In M. S. Clark \& S. T. Fiske (Eds.), Affect and cognition. Hillsdale, NJ: Erlbaum.

Linville, P. W. (1987). Self-complexity as a cognitive buffer against self-related illness and depression. Journal of Personality and Social Psychology, 52, 663-676.

Markus, H., \& Nurius, P. (1986). Possible selves. American Psychologist, 4I, 954-969.

Markus, H., \& Wurf, E. (1987). The dynamic self-concept: A social psychological perspective. Annual Review of Psychology, 38, 299-337.

Oyserman, D., \& Markus, H. (1989). Possible selves and delinquency. Unpublished paper.

Rogers, C. R. (1951). Client-centered therapy. Boston: Houghton Mifflin.

Safran, J. D., Segal, Z. V., Hill, C., \& Whiffen, V. (1990). Refining strategies for research on self-representations in emotinal disorders. Cognitive Therapy and Research, 14, $143-160$.

Schwartz, R. M., \& Garamoni, G. L. (1986). A structural model of positive and negative states of mind: Asymmetry in the internal dialogue. Advances in cognitive behavioral research and therapy. Orlando, FL: Academic Press.

Segal, Z. V. (1988). Appraisal of the self-schema construct in cognitive models of depression. Psychological Bulletin, 103, 147-162.

Segal, Z. V., \& Vella, D. D. (1990). Self-schema in major depression: Replication and extension of a priming methodology. Cognitive Therapy and Research, 14, 161-176.

Showers, C. (1989b). The organization of positive and negative components of the self. Unpublished manuscript, Barnard College, New York.

Singer, J. L., \& Salovey, P. (1985). Organized knowledge structures and personality: Schemas, self-schemas, prototypes, and scripts. Presented at Program on Conscious and Unconscious Mental Processes of the John O. and Katherine T. MacArthur Foundation. Center of Advanced Study of Behavioral Sciences, Stanford, CA.

Stein, K. F. (1989). Structure of the self and coping with threatening feedback. Unpublished manuscript, University of Michigan.

Stern, D. N. (1985). The interpersonal world of the infant. New York: Basic Books.

Sullivan, H. S. (1953). The interpersonal theory of psychiatry. New York: Norton. 
Trevarthen, C. (1980). The foundations of intersubjectivity: Development of interpersonal and cooperative understanding in infants. In D. R. Olson (Ed.), The social foundation of language and thought: Essays in honor of Jerome Bruner. New York: Norton.

Wurf, E. (1989). Negativity in the self-concept: Self-construal and feedback-seeking. Unpublished doctoral dissertation, University of Michigan, Ann Arbor, MI.

Zajonc, R. B (1960). The processes of cognitive tuning in communication. Journal of Abnormal Social Psychology, 61, 159-168. 